\title{
Ardahan ve Çevresinde Yabani Olarak Yetişen Gilaburu Meyve Ekstraktının Antimikrobiyal, Antioksidan ve Antimutajenik Aktivitelerinin Araştırılması
}

\author{
Investigation of Antimicrobial, Antioxidant, and Antimutagenic Activities of Wild Guelder \\ RoseFruit Extract Grown in Ardahan and Its Surrounding Area
}

\author{
Mehmet ARSLAN ${ }^{1, a}$, Nurcan ERBİL ${ }^{1, b}$, Zehra Tuğba MURATHAN ${ }^{* 2, c}$ \\ ${ }^{1}$ Ardahan Üniversitesi Sağllk Bilimleri Yüksekokulu Hemşirelik Bölümü, Ardahan \\ ${ }^{2}$ Ardahan Üniversitesi Mühendislik Fakültesi, Glda Mühendisliği Bölümü, Ardahan
}

\author{
• Geliş tarihi / Received: 23.02.2017 • • Düzeltilerek geliş tarihi / Received in revised form: 18.09.2017 • Kabul tarihi / Accepted: 19.09.2017
}

\begin{abstract}
Öz
Bu çalışmada Ardahan ve çevresinde doğal olarak yetişmekte olan Gilaburu meyvelerinin antioksidan özellikleri, farklı mikroorganizmalar üzerindeki antimikrobiyal etkisi ve Ames testi ile antimutajenik etkisi araştırıldı. Antimikrobiyal aktivite testleri esnasında farklı Gr (+) ve Gr (-) bakteriler ile mayalar kullanıldı. Antimutajenik etki çalışmalarında ise AMES/Salmonella Mikrozom testi ile Salmonella typhimurium TA 98 ve TA 100 suşları kullanıldı. Elde edilen verilere göre gilaburu meyvelerinin ağırlığı ortalama olarak $0.80 \mathrm{~g}$, suda çözünür kuru madde (SÇKM) içeriği \% 11.3, pH's1 3.20 , toplam antosiyanin miktarı $0.80 \mathrm{mg} / \mathrm{g}, 1,1$-diphenyl-2-picrylhydrazyl (DPPH)radikal süpürücü etkisi \% 52.5, 2,2'Azino-bis (3-ethylbenzothiazoline-6-sulfonic acid) (ABTS) değeri $72.8 \mu \mathrm{mol} \mathrm{TE} / \mathrm{g}$ FW, Ferric Reducing Antioxidant Power (FRAP) değeri ise $122.6 \mu \mathrm{mol} \mathrm{Fe} \mathrm{II/g} \mathrm{FW} \mathrm{olarak} \mathrm{belirlendi.} \mathrm{Ayrıca} \mathrm{gilaburu} \mathrm{ekstraktının} \mathrm{test} \mathrm{mikroorganizmaları}$ üzerinde değişen oranlarda antibakteriyel aktiviteye sahip oldukları; ancak antifungal aktivite sergilemedikleri belirlendi. Test bakterileri içerisinde ise en duyarlı olanının Pseudomonas aeruginosa ATCC 9027 olduğu belirlendi. Antimutajenite deneylerinde,TA98 suşlarında gilaburunun sadece $40 \mu \mathrm{l}$ dozunda pozitif kontrole göre önemli bir azalma meydana getirdi. TA100 suşlarında ise hiçbir dozda pozitif kontrole göre istatistiksel olarak önemli bir azalma meydana gelmediği belirlendi.
\end{abstract}

Anahtar kelimeler: Antimikrobiyal, Antimutajen, Antioksidan, Gilaburu, Viburnum opulus

\begin{abstract}
In this study, antioxidant activity, antibacterial effect against some test bacteria, and antimutagenic effect with AMES test of Guelder rose fruit naturally growing in Ardahan and its surrounding area were examined. Different Gr (+), and Gr (-) bacteria and yeasts were used as test microorganisms during the antibacterial activity tests. AMES / Salmonella/Microsome test was preferred for antimutagenic effect study and Salmonella typhimurium TA 98 and TA 100 strains were used. According to the obtained data, $0.80 \mathrm{~g}$ fruitweight on average, $11.3 \%$ of Soluble Dry Matter content, 3.20 of pH, $0.80 \mathrm{mg} / \mathrm{g}$ of total anthocyanin, and 52.5\% of 1,1-diphenyl-2-picrylhydrazyl (DPPH) radical scavenging activity, $72.8 \mu \mathrm{mol} \mathrm{TE} / \mathrm{g} \mathrm{FW} \mathrm{2,2'-Azino-bis} \mathrm{(3-ethylbenzothiazoline-6-sulfonic} \mathrm{acid)} \mathrm{(ABTS)} \mathrm{value,} 122.6$ umol Fe II/g FW Ferric Reducing Antioxidant Power (FRAP) value were determined. It was determined that Guelder rose fruit extract has antibacterial activity at different rates on test bacteria, but not antifungal activity. The most sensitive bacterium was Pseudomonas aeroginosa ATCC 9027 among the test microorganisms. In antimutagenic activity, only $40 \mu \mathrm{l}$ dose of Guelder rose in TA98 strains caused a significant reduction compared to the positive control. In TA100 strains, no statistically significant decrease compared to positive control at any dose occurred.
\end{abstract}

Keywords: Antimicrobial, Antimutagenic, Antioxidant, Guelder rose, Viburnum opulus

*c Zehra Tuğba MURATHAN; zehratugbaabaci@ardahan.edu.tr; Tel: (0478) 2115000 (dahili: 2314); orcid.org/0000-0002-1468-7240
$\begin{array}{ll}\text { a } \text { orcid.org/0000-0002-9015-1798 } & \text { b orcid.org/0000-0001-9553-2306 }\end{array}$ 


\section{Giriş}

Türkiye birçok meyve türünün gen merkezi ve doğal yayılma alanıdır. Bugün dünyada yetiştirilmekte olan 138 kadar meyve türünün $75^{\prime} \mathrm{i}$ Türkiye'de yetiştirilmektedir. Türkiye'de görülen bu tür zenginliği yanında çeşit bolluğu da mevcuttur (Özbek, 1977; Orakçı, 2010). Ardahan ve çevresinde yabani olarak yetişen gilaburu (Viburnum opulus L.), Hanımeligiller (Caprifoliaceae) familyasından olup; kışın yaprağını döken, 2-4 metre boylanabilen bir bitkidir. Meyvesi nohut büyüklüğünde ve kırmızı renkte olup, Ağustos-Eylül aylarında olgunlaşır. Meyvelerin yaklaşık 30-40 tanesi bir salkım oluşturur ve acımsı bir tadı vardır (Bolat ve Özcan 1995; Orakç1, 2010).

Daha önce yapılan birçok çalışma meyve tüketiminin kanserden diyabete, kardiyovasküler hastalıklardan sinir hastalıklarına kadar birçok hastalığa yakalanma riskini azalttığını göstermiştir. $\mathrm{Bu}$ durum meyve ve sebzelerde bulunan fenolik bileşiklerin antioksidan etkisinden kaynaklanmaktadır. Ayrıca; fenolik bileşikler büyük yapısal farklılıklara sahiptir ve sekonder metabolitlerin en fazla çeşitlilik gösteren gruplarından bir tanesidir. Bu gruplar, bakteri hücre membranın yapısını bozarak hücresel bileşenlerin membrandan dışarıya doğru sizmasina neden olurlar ve membranda meydana gelen bu bozulmaya fenolik bileşiklerdeki hidroksil (-OH) gruplarının gösterdiği inhibitör etkinin sebep olduğu düşünülmektedir. Bunun yanında fenolik bileşikler antioksidan etkiye sahip olduklarından bitkisel ağırlıklı beslenme ile fenolik bileşiklerin yoğun alınmasından dolayı radikal oluşumunu azaltarak kanser ve damar hastalıkları riskini düşürürler (Sağıroğlu, 2003; Özcan, 2010). Bu bakımdan bitkilerdeki fenolik bileşiklerin güvenilir ve pratik yöntemlerle tayin edilmesi çok önemlidir.

Günümüzde insanlar tarafından besin amaçlı olarak tüketilen veya geleneksel tıpta kullanılan bitkisel kökenli ürünlerin birçoğunda toksik etki gösteren maddelerin bulunduğunun da malesef yeterince farkına varılamamıştır. Örneğin bitkisel kökenli ürünlerde bulunan uçucu yağların bazıları ciddi yan etkilere sahiptir (Franzios vd., 1997; Stammati vd., 1999; Ipek ve ark., 2003; Azirak ve Rencüzogullari, 2008; Buyukleyla ve Rencuzogullari, 2008). Bu maddelerin en büyük tehlikeleri de mutasyon ve/veya kansere sebep olabilme riskleridir. Bundan dolayıdır ki bu ürünlerin insan genomunda mutasyonlara sebep olup olmadıklarının veya mutasyonları azaltıp azaltmadıklarının ortaya koyulması oldukça önemlidir. Türkiye'de yetiştiriciliği pek yaygın olmayan bir yenilebilir meyve bitkisi olan gilaburunun birçok özelliğinin incelenmesi gerekmektedir. $\mathrm{Bu}$ çalışma, Gilaburu meyve ekstraktının antimikrobiyal, antioksidan ve antimutajenik aktivitelerini ortaya çıkarmak amacıyla yapılmıştır.

\section{Materyal ve Metot}

\section{1. Örneklerin Temini}

Gilaburu meyve örnekleri 2015 y1lı Eylül ayında Ardahan Üniversitesi Meslek Yüksekokulu bahçesinden toplandı ve uygun koşullarda laboratuvar ortamına getirilerek taze olarak çalışıldı.

\subsection{Ekstraksiyon}

40 gram taze gilaburu meyvesi tartilarak $200 \mathrm{ml}$ saf su ile homojenizatörde (IKA T 18, Çin) homojenize edildikten sonra 72 saat süre ile 190 rpm'de ekstrakte edildi. 72 saat sonrasinda 5000 g'de $10 \mathrm{dk}$ satrifüj edildi ve süpernatant kısmı alındı. Elde edilen bu ekstrakt rotary evaporatörde konsantre edildikten sonra kullanılana kadar $20^{\circ} \mathrm{C}$ 'de muhafaza edildi. Elde edilen bu ekstrakt antimikrobiyal ve antimutajenik aktiviteler için kullanıldı.

\subsection{Meyve Ă̆ırlı̆̆ı, Suda Çözünür Kuru Madde (SÇKM), pH ve Titre Edilebilir Asitlik Analizleri}

10 tane meyve örneği 0.2 g'a duyarlı dijital hassas terazide (Desis T 28, İstanbul, Türkiye) tartıldı. Meyvelerin suda çözünür kuru madde içerikleri 22 ${ }^{\circ} \mathrm{C}$ 'de Mettler-Toledo $30 \mathrm{P}$ dijital refraktometre (Mettler-Toledo International Inc., İsviçre) ile, \% asitlik değerleri ise titrimetrik metod kullanılarak Cemeroğlu (1992)'na göre belirlendi.

\subsection{Toplam Antosiyanin Tayini}

Toplam antosiyanin tayini Giusti ve Wrolstad (2001)'a göre belirlendi. Örnek $5 \mathrm{~g}$ meyve $10 \mathrm{ml}$ $\% 1 \mathrm{HCl}$ içeren metanol çözeltisinde $2 \mathrm{dk}$ homojenize edildi ve bir gece bekletildikten sonra filtre kâğıdından (Whatman No: 2) süzüldü. Süzüntü pH $1.0(0.2 \mathrm{~N} \mathrm{KCl}, 0.2 \mathrm{~N} \mathrm{HCl})$ ve $\mathrm{pH} 4.5$ $(\mathrm{CH} 3 \mathrm{CO} 2 \mathrm{Na} .3 \mathrm{H} 2 \mathrm{O}, 0.1 \mathrm{~N} \mathrm{HCl})$ tamponları içinde $15 \mathrm{dk}$ inkübasyona birakıldı ve absorbansları çözücüye karşı 530 ve 700 nm'lerde spektrofotometrik (Unico S1205, USA) olarak ölçüldü. 


\subsection{Antioksidan Kapasite Tayini}

\subsubsection{DPPH (1,1-diphenyl-2-picrylhydrazyl) Yöntemi}

Antioksidan kapasite (serbest radikallerin indirgenme kapasitesi) DPPH metodu ile süpürücü etkiye göre belirlendi. Örnek $2 \mathrm{~g}$ meyve örneği,2 ml ekstraksiyon çözeltisi (\% 85 metanol, $\% 15$ asetik asit) ile karıştırılarak homojenize edildi ve 24 saat $4{ }^{\circ} \mathrm{C}$ 'de bekletildi. Daha sonra 10 dk 10000 g'de santrifüj edildi. DPPH çözeltisi $(950 \mu 10.1 \mathrm{~N})$ seyreltilmiş $50 \mu \mathrm{l}$ meyve ekstraktı ile birleştirildi. Çözelti $30 \mathrm{dk}$ karanlık bir ortamda, oda sicaklığında inkübe edildi. Daha sonra örnekler ve standart $515 \mathrm{~nm}$ dalga boyunda spektrofotometrede okundu. Antioksidan kapasite $\% \mathrm{DPPH}=\left(\mathrm{A}_{\text {kontrol}}-\mathrm{A}_{\text {örnek }}\right) / \mathrm{A}_{\text {kontrolX }} 100$ formülüyle hesaplandı (Bakhshi ve Arakawa, 2006; Rezaeirad vd., 2013).

\subsubsection{ABTS (2,2'-Azino-bis(3-} ethylbenzothiazoline-6-sulfonic acid)) Yöntemi

ABTS yöntemi Re vd. (1999)'a göre yapıldı. 25 $\mathrm{ml} 7 \mathrm{mM}$ ABTSve $25 \mathrm{ml} 2.45 \mathrm{mM}$ potasyum per sülfat ile 1:1 oranında stok çözelti hazırlandı ve 16 saat oda sicaklığında karanlık ortamda inkübe edildi. Analizler için stok çözelti absorbansı 734 nm'de $0.7 \pm 0.05$ olana kadar etanolle dilüe edildi. $1000 \mu 1$ dilüe örnek $3.8 \mathrm{ml}$ ABTS çözeltisiyle karıştırıldı ve 6 dk oda sıcaklığında inkübe edildikten sonra 734 nm'de absorbansı ölçüldü. Standart olarak troloks kullanıldı ve sonuçlar ug Troloks/g cinsinden hesapland.

\subsubsection{FRAP (Ferric Reducing Antioxidant Power) Yöntemi}

FRAP yöntemi Benzie ve Strain (1996) ile Ahmad ve Mukhtar (1999)'a göre yapıldı. FRAP ajanı 25 $\mathrm{ml}$ sodyum asetat tampon (300 mM, pH 3.6), 2.5 $\mathrm{ml}$ TPTZ (Tripyridil-s-triazine) çözeltisi $(10 \mathrm{mM}$, $40 \mathrm{mM}$ HCl'de çözdürülmüş) ve $2.5 \mathrm{ml}$ $\mathrm{FeCl}_{3} 6 \mathrm{H}_{2} \mathrm{O} \quad(20 \mathrm{mM})$ karışımıyla hazırlandı. $37^{\circ} \mathrm{C}$ 'de su banyosunda 1 sitıld 1 ve $900 \mu \mathrm{l}$ 'si bir küvete alınarak başlangıç absorbans değeri okundu. Dilüe (1:4 v/v su) örneğin $100 \mu \mathrm{l}$ 'si küvete alındı ve üzerine 3 ml FRAP ajanı eklendi. $4 \mathrm{dk}$ sonra absorbans $593 \mathrm{~nm}$ 'de ölçüldü. Standart eğri $\mathrm{FeSO}_{4}$ çözeltisi kullanılarak hazırlandı (100$1000 \mu \mathrm{l})$. Sonuçlar $\mu \mathrm{mol} \mathrm{Fe}$ (II) $/ \mathrm{g}$ cinsinden hesapland1.

\subsection{Antibakteriyel Aktivite Testi}

Antibakteriyel aktivite testi oyuk agar metodu ile çalışılmış olup (Özçelik, 1992); test mikroorganizmas1 olarak Bacillus subtilis, Staphylococcus aureus ATCC 6538, Bacillus megaterium DSM 32, Enterobacter aerogenes, Escherichia coli, Pseudomonas aeroginosa ATCC 9027, Bacillus licheniformis ve Klebsiella pneumoniae bakterileri ile Yarrovi lipolytica ve Sacharomyces cerevisiae mayaları kullanıldı. Steril edilmiş olan Müller Hinton Agar içerisine 18 saatlik $\left(1 \times 10^{8} \mathrm{cfu} \mathrm{ml}^{-1}\right)$ bakteri kültürlerinin her birinden $100 \mu \mathrm{l}$ aşlandıve tam olarak katılaştığından emin olunan plaklara aseptik koşullarda korkbor yardımı ile $11 \mathrm{~mm}$ çapında açılan her bir kuyucuğun içerisine $150 \mu$ l gilaburu meyve ekstraktı eklendi. Pozifif kontrol olarak standart bir antibiyotik olan Penisilin G (P 10), negatif kontrol olarak ise distile su kullanıldı. Her bir petri plağ $37{ }^{\circ} \mathrm{C}^{\prime} \mathrm{de} \quad 48$ saat süre ile inkübasyona bırakıldı. Çalışmalar üç tekrarlı yapılarak zon çapları dijital kumpas ile mm olarak ölçülmüştür.

\subsection{Ames/Salmonella/Mikrozom Testi}

\subsubsection{Test Suşları}

Antimutajenik aktivitenin ölçülebilmesi için Ames testi tercih edilmiş olup, uygulamalarda S9 mix yokluğunda S. typhimurium'un TA 98 ve TA 100 suşları kullanıldı. Bu suşlardan $S$. typhimurium TA 98 çerçeve kayması, S. typhimurium TA 100 ise baz çifti değişimi mutasyonlarına neden olan kimyasallara karşı duyarlı1ık göstermektedir. $\mathrm{Bu}$ suşlar düzenli olarak Rfa mutasyonu, $\mathrm{R}$ faktör varlığı, kristal viyole duyarlılığı, histidin ihtiyacı, $\mathrm{UVr}$ B mutasyonu, ampisiline dirençlilik ve spontan geri dönüş oranları için Maron ve Ames (1983) tarafindan önerilen metoda göre kontrol edildi.

\subsubsection{Sitotoksik Etkinin Belirlenmesi}

Gilaburu meyve ekstraktının S. typhimurium'un TA 98 ve TA 100 suşları üzerinde öldürücü olmayan dozlarının belirlenmesi amaciyla, 16 saat inkübe edilmiş olan bakteri kültürlerinin her birinden (yaklaş1k $1 \times 10^{9}$ bakteri $\mathrm{ml}^{-1}$ ) $100 \mu 1$ ve ekstraktın değiş̧ik derişimlerdeki çözeltisinden (5$80 \mu \mathrm{l}$ plak $^{-1}$ ) alınarak, $2 \mathrm{ml}$ top agar içerisine eklendi. Bu karışım homojen bir şekilde karıştırıldıktan sonra minimal glukoz agar (MGA) besiyeri içeren plaklara ince bir tabaka halinde dökülerek $37^{\circ} \mathrm{C}^{\prime}$ de $48-72$ saat süre ile inkübe edildi. İnkübasyondan sonra ekstraktın değişik derişimlerini içeren plaklarda gelişen koloni sayıları ile kontrol plaklarında gelişen koloni sayıları karşılaştırıldı. Elde edilen sonuçlar neticesinde ekstraktın $80 \mu$ lplak $^{-1}$ dozunun toksik 
özellik gösterdiği belirlendi ve toksik özellik göstermediği gözlenen dört doz (40 $\mu 1 \mathrm{plak}^{-1}, 20$ $\mu 1$ plak $^{-1}, 10 \mu 1$ plak $^{-1}$ ve $5 \mu 1$ plak $\left.^{-1}\right)$ mutajenite testlerinde kullanıldı. Sitotoksik dozun $\mathrm{LD}_{50}$ (ortalama öldürücü doz)'nin altında olması gerekmektedir. $\mathrm{Bu}$ nedenle deneme plaklarındaki koloni sayısı kontrol plağındaki koloni sayısının yarısının altında olmaması durumunda, doz toksik olarak kabul edilmemektedir.

\subsubsection{Antimutajenite Testi}

Antimutajenite testi plak inkorporasyon tekniği modifiye edilerek yapıldı (Maron ve Ames, 1983). Analizler esnasında, histidin ve biyotin eklenmiş olan $2 \mathrm{ml}$ top agar içerisine 16 saatlik bakteri kültürlerinin (yaklaşık $1 \times 10^{9}$ bakteri $\mathrm{ml}^{-1}$ ) her birinden $100 \mu 1$, pozitif kontrol olarak TA98 suşu için $100 \mu \mathrm{g} /$ petri 4-nitro-o-fenilendiamin (4NPD), TA100 suşu için ise $10 \mu \mathrm{g} /$ petri sodyum azid (SA) ve ekstraktın toksik olmadığı belirlenen dozları eklendikten sonra homojen bir şekilde karıştırıldı ve MGA besiyeri içeren plaklara ince bir tabaka halinde döküldü. Pozitif kontrol olarak TA 98 suşu için 4-NPD (100 $\mu \mathrm{g}$ petri), TA 100 suşu için SA $(10 \mu \mathrm{g}$ petri) kullanıldı. Petriler $37^{\circ} \mathrm{C}$ 'de 48-72 saat inkübe edildi. Analizler sonucunda kontrol ve test plaklarında gelişen revertant koloni sayıları belirlendi ve istatistiksel olarak karşılaştırıldı.

\section{8. İstatistiksel Analizler}

Her çalışma üç tekrarlı olarak yapıldı. Çalışmalardan elde edilen bulguların istatistiksel yönden değerlendirilmesinde SPSS 16 programı kullanildı. Tespit edilen antimutajenite analizlerinde belirlenen ortalamalar ile kontrol ve deney grupları arasında değişiklik gösterip göstermediği varyans analizi kullanılarak belirlendi. Varyans analizi için one way Anova testlerinden Dunnett testi kullanıldi. Elde edilen veriler 0.05 anlam seviyesi göz önünde bulundurularak yorumland.

\section{Bulgular ve Tartışma}

$\mathrm{Bu}$ çalışmada kullanılan aktivite tayin yöntemleri, kısa zamanda sonuç veren, düşük maliyetli, güvenilir ve bilim dünyasında herkesçe kabul edilen yöntemler oldukları için tercih edilmişlerdir. Çalışmalar sonucunda biyokimyasal aktivite sonuçlarına göre, gilaburu meyvelerinin ağırlığ ortalama olarak $0.80 \mathrm{~g}$, SÇKM miktarı \% 11.3, pH's1 3.20, toplam antosiyanin miktar1 ise $0.80 \mathrm{mg} / \mathrm{g}$ olarak tespit edildi (Tablo 1). Konuyla alakalı yapılan bir çalışmada Kayseri ili Bünyan,
Melikgazi, Develi ve Akkışla ilçelerinde yetişen gilaburu meyvelerinin ortalama meyve ağırlı̆ 1 0.70-0.73 g, SÇKM miktarı \% 10.0-10.5, pH's1 ise2.83-3.14 olarak tespit edilmiştir (Gündoğar, 2012). Tarafimızca yapılan bu çalışmada elde edilen değerlerin Gündoğar (2012) tarafından elde edilen verilere göre daha yüksek olduğu görülmektedir. Bitkilerden elde edilen ekstraktların içeriği bitkinin habitatı ile yakından ilgili olduğu ve içerik miktarının da değişebileceği bildirilmiştir (Papageorgiou vd., 2008; Koliopoulos vd., 2010).

Tablo 1. Meyve ağırlığı, suda çözünür kuru madde (SÇKM), pH ve toplam antosiyanin miktarı.

\begin{tabular}{ccccc}
\hline & $\begin{array}{c}\text { Ortalama } \\
\text { Meyve } \\
\begin{array}{c}\text { Ağırlığ1 } \\
(\mathrm{g})\end{array}\end{array}$ & $\begin{array}{c}\text { SÇKM } \\
(\%)\end{array}$ & $\mathrm{pH}$ & $\begin{array}{c}\text { Antosiyanin } \\
\text { Miktar } \\
(\mathrm{mg} / \mathrm{g})\end{array}$ \\
\hline Gilaburu & $0.80 \pm 0.02$ & $11.3 \pm 0.1$ & $3.20 \pm 0.9$ & $0.80 \pm 0.8$ \\
\hline
\end{tabular}

Orakçı (2010), Kayseri'den toplanan yaş gilaburu metanol ekstresinde toplam antosiyanin miktarını $0.47 \mathrm{mg} / \mathrm{g}$,yaş gilaburu sulu ekstresinde 0.27 $\mathrm{mg} / \mathrm{g}$, kuru gilaburu metanol ekstresinde ise 0.12 $\mathrm{mg} / \mathrm{g}$ olarak bulmuştur. Çalışmamızdan elde edilen değer $(0.80 \mathrm{mg} / \mathrm{g})$ bu çalışmadan elde edilen değerlere göre dedaha yüksektir. Bu durumun meyvenin toplandığg coğrafik bölgelerin farklı olmasından kaynaklanabileceği düşünülmektedir.

Antioksidan aktivite sonuçları incelendiğinde ABST değerinin $72.8 \mu \mathrm{mol}$ TE /g FW, FRAP değerinin $122.6 \mu \mathrm{mol} \mathrm{Fe} \mathrm{II/g} \mathrm{FW} \mathrm{ve} \mathrm{DPPH}$ değerinin ise \% 52.5 olduğu belirlenmiştir (Tablo 2). Daha önce yapılan çalışmalarda bazı Viburnum türlerinin oksidanlara karşı insan sağlığını korumakla görevli olan polifenolikleri yoğun olarak içerdikleri bildirilmiştir (Česonienèet vd., 2010; Kraujalytė vd., 2013). Altun vd. (2008), gilaburunun antioksidan aktivitesini DPPH radikalini süpürücü etkileri bakımından incelemişler, dal ve meyve ekstrelerinin 0.014 $\mathrm{mg} / \mathrm{mL}$ ve $0.057 \mathrm{mg} / \mathrm{mL} \mathrm{IC} 50$ değerlerine sahip olduğu tespit etmişlerdir. Burnaz (2007) ise DPPH radikalini süpürmede meyve çekirdekleri metanol ekstresinin $0.0047 \mathrm{mg} / \mathrm{mL}$, meyve suyunun $0.0096 \mathrm{mg} / \mathrm{mL} \mathrm{IC}_{50}$ değerine sahip olduğunu tespit etmiştir. Başka bir çalışmada ise Şeker vd. (2016) gilaburu meyve posası eklenmiş keklerin toplam fenolik içeriği ve radikal temizleme aktivitesi değerlerinin, meyve posası katılma seviyesine göre orantılı olarak arttığını bulmuşlardır. 
Tablo 2. Gilaburu örneklerine ait antioksidan aktivite sonuçları.

\begin{tabular}{cccc}
\hline & $\begin{array}{c}\text { ABTS } \\
(\mu \mathrm{mol} \mathrm{TE} / \\
\mathrm{g} \mathrm{FW})\end{array}$ & $\begin{array}{c}\text { FRAP } \\
(\mu \mathrm{mol} \mathrm{Fe} \mathrm{II} / \\
\mathrm{g} \mathrm{FW})\end{array}$ & $\begin{array}{c}\text { DPPH } \\
(\%)\end{array}$ \\
\cline { 2 - 4 } Gilaburu & $72.8 \pm 0.6$ & $122.6 \pm 4.8$ & $52.5 \pm 3.3$ \\
\hline
\end{tabular}

Antibakteriyel aktivite sonuçlarına bakıldığında gilaburu ekstraktının test mikroorganizmaları üzerinde değişen oranlarda antibakteriyel aktiviteye sahip olduğu; ancak antifungal aktivite sergilemediği görülmektedir (Tablo 3). Test bakterileri içerisinde ise en duyarlı olanının Pseudomonas aeruginosa ATCC 9027 olduğu belirlenmiştir $(21 \pm 0.577 \mathrm{~mm})$. Gilaburudan elde edilen farklı ekstraktların antimikrobiyal aktivitesi farklı çalışmalarda denenmiştir. Bu çalışmalardan biri Yürüker vd. (1993) tarafından yapılmış olup, gilaburu meyvelerinin sulu ekstrelerinin influenza virüsünün infeksiyon etkisini inhibe ettiğini belirlemişlerdir. Benzer bir çalıșma da Burnaz vd. (2007) tarafindan yapılmış ve Viburnum opulus'tan elde edilen kloroform ve metanol ekstrelerinin antimikrobiyal etkinliğe sahip olduğu bildirilmiştir.

Hizlısoy (2009) Kayseri'den toplanan Gilaburu meyve ekstresinin S.aureus, E.coli ve $P$. aeruginosa bakterileri üzerinde antimikrobiyal etkinlik gösterdiğini tespit etmiştir. Bizim çalışmamızdan elde edilen veriler de bu sonucu desteklemektedir. Yine benzer bir çalışmada $V$. opulus ekstraktlarının Staphylococcus aureus ve $S$. epidermidis üzerindeki inhibitör etkisi tespit edilmiştir (Bubulica vd., 2012). Sagdıç vd. (2006) de $V$. opulus kuru meyvelerin metanol özütlerinin (\% 10-15) patojenik ve bozulma bakterilerine karş1 antimikrobiyal aktivitesinin olduğunu bildirilmiştir. Antibakteriyel etki, V. opulus meyve tohumu yağı üzerinde yapılan bir çalışmada da tarif edilmiştir (Yilmaz vd., 2008).

Česoniene vd. (2014) V. opulus genotiplerinin meyve suları ile etanol ekstraktlarının antimikrobiyal aktivitelerini karşılaştırmışlardır. En etkili antibakteriyel aktivite değerlerinin $S$. typhimurium, $S$. agona ve $L$. monocytogenes'e karş1, sırasıyla 23.6, 20.7 ve $19.1 \mathrm{~mm}$ inhibisyon zonlarına sahip olduğunu belirlemişlerdir. Çalışmada Staphylococcus epidermidis ve Micrococcus luteus'un sirasiyla 14.2 ve $15.0 \mathrm{~mm}$ minimum inhibisyon zonları ile en yüksek dirence sahip olduğu bildirilmiştir. Meyve sularının etanol özlerine kiyasla daha fazla antibakteriyel etki gösterdiği belirlenmiştir. Bunun aksine, maya kültürlerinin büyümesinin, meyve suları ve etanol özütlerine az veya hiç duyarlılık göstermediği bildirilmiştir. Česoniene vd. (2012) ise V. opulus meyve ekstrelerinin hem Gram (+) hem de Gram (-) bakterilere karşı antimikrobiyal etki gösterdiğini, mayalara karşı herhangi bir etkinin olmadığını bulmuşlardır.

Eryılmaz vd. (2013) de test ettikleri Viburnum türlerinin etanol ekstraktlarının sulu özütlere kıyasla daha iyi antimikrobiyal aktivite sergilediğini tespit etmişlerdir. İskender vd. (2007) ise yapılan diğer çalışmaların aksine Vibernum opulus'tan elde edilen uçucu yağların ise test mikroorganizmalarına etki etmediğini tespit etmişlerdir. Antimikrobiyal aktivite çalışmalarında elde edilen sonuçlar bakteri türü ve suşuna, bitkinin yetişme ve saklanma koşullarına, ekstraksiyon şekline ve test esnasında kullanılan madde miktarına göre değişiklik gösterebilmektedir.

Tablo 3. Gilaburu ekstraktlarına ait antimikrobiyal aktivite sonuçları

\begin{tabular}{lll}
\hline Mikroorganizma & Gilaburu ekstraktı (mm) & Penisilin G (mm) \\
\hline Klebsiella pneumoniae & $18.66 \pm 0.33$ & $9 \pm 0.00$ \\
\hline Pseudomonas aeroginosa ATCC 9027 & $21.00 \pm 0.57$ & $12.33 \pm 0.33$ \\
\hline Bacillus subtilis & $18.66 \pm 0.33$ & $9 \pm 0.00$ \\
\hline Escherichia coli & $18.00 \pm 0.57$ & $8.33 \pm 0.66$ \\
\hline Staphylococcus aureus ATCC 6538 & $18.33 \pm 0.33$ & $8.33 \pm 0.33$ \\
\hline Bacillus megaterium DSM 32 & $19.00 \pm 0.57$ & $8.67 \pm 0.33$ \\
\hline Bacillus licheniformis & $18.00 \pm 0.00$ & $16.67 \pm 1.20$ \\
\hline Enterobacter aerogenes & $18.66 \pm 0.33$ & $10.33 \pm 0.33$ \\
\hline Yarrovia lipolytica & - & - \\
\hline Saccharomyces cerevisiae & - & - \\
\hline
\end{tabular}


Antimutajenite deneyleri sonucunda gilaburunun sadece $40 \mu 1$ dozunda TA98 irklarında pozitif kontrolle göre önemli bir azalma meydana getirdiği tespit edilmiştir $(p=0,019)$. TA100 ırklarında ise hiçbir dozda pozitif kontrole göre istatistiksel olarak önemli bir azalma meydana gelmemiştir. Elde edilen veriler incelendiğinde revertant koloni sayısının TA98 suşlarında tüm dozlarda pozitif kontrolle göre azalmalar meydana gelmiş ancak sadece en yüksek doz istatistiksel olarak önemli bulunmuştur. TA 100 suşlarında ise $5 \mu 1,20 \mu 1,40 \mu 1$ dozlarda pozitif kontrole göre azalmalar meydana gelmiş ancak bu azalmalar istatistiksel olarak anlamsız bulunmuştur. Muameleli gruplardaki revertant koloni sayısi ise kontrol ile muamele edilen gruplara nazaran önemli derecede yüksek çıkmıştır. $\mathrm{Bu}$ da antimutajenite deneylerinde beklediğimiz bir sonuçtur (Tablo 4).

Tablo 4. Gilaburu ekstraktlarına ait farklı dozların S.typhimurium TA 98 ve TA100 suşları üzerinde antimutajenik etkileri

\begin{tabular}{lccc}
\hline Test Maddesi & Konsantrasyon $(\boldsymbol{\mu g} / \mathbf{p e t r i})$ & TA 98 & TA 100 \\
\hline Kontrol & & $17.3 \pm 0.3$ & $82.33 \pm 2.33$ \\
4-NPD $^{(1)}$ & 100 & $1908 \pm 142^{\mathrm{a} 3}$ & - \\
SA $^{(2)}$ & 10 & - & $2570 \pm 65.2^{\mathrm{a} 3}$ \\
Gilaburu $_{\text {Gilaburu }}$ & $5 \mu 1$ & $1712.7 \pm 91.7^{\mathrm{a} 3}$ & $2489 \pm 236^{\mathrm{a} 3}$ \\
Gilaburu & $10 \mu \mathrm{l}$ & $1623 \pm 164^{\mathrm{a} 3}$ & $2859 \pm 185^{\mathrm{a} 3}$ \\
Gilaburu & $20 \mu \mathrm{l}$ & $1567.3 \pm 98.6^{\mathrm{a} 3}$ & $2222 \pm 285^{\mathrm{a} 3}$ \\
\hline
\end{tabular}

*Revertant kolonilerin tespiti için toplam üç petri kutusu değerlendirilmiştir, (1): 4-nitrophenylene diamine, (2): Sodyumazid, a: kontrol ile aradaki fark anlaml, b: Pozitif kontrol ile aradaki fark anlaml1, alb1c1:p<0.05, a2b2c2: $\mathrm{p}<0.01, \mathrm{a} 3 \mathrm{~b} 3 \mathrm{c} 3: \mathrm{p}<0.001$

Bitkilerin çoğunluğunun toksik ve genotoksik bileşikleri vardır. Bunlar antioksidan, antimutajenik ve antikanser özelliklere sahip polifenolik bileşikler olabileceği gibi, konsantrasyonlarının yüksek miktarda bulunması sonucu prooksidan ve mutajenik özelliklere de sahip olabilirler (Mennen vd., 2005; Wan-Ibrahim vd., 2010). Bu nedenle, zengin antioksidan polifenol kaynağı olan bitkilerin aşırı kullanımının toksisiteye neden olabileceği konusu endişe yaratabilmektedir (Paulauskas vd., 2015). Bu nedenle bu bitkilerin biyolojik özelliklerinin iyi araştırılması gerekmektedir.

Paulauskas vd. (2015) V. opulus ve V. sargentii Koehne meyve sularının comet testi ve mikronukleus testlerinde genotoksik olmadığını ve Ames testinde S9 mix (metabolik aktivatör) yokluğunda ve varlığında $S$. TyphimuriumTA98 ve TA100 suşlarında geri dönüş kolonilerinin sayısında belirgin bir artış göstermediğini tespit etmişlerdir. Bizim yaptığımız çalışmada ise farklı olarak TA98 suşlarında gilaburunun $40 \mu \mathrm{l}$ dozu antimutajen özellik göstermiştir.

\section{Sonuç}

Sonuç olarak, gilaburu meyve ekstraktının önemli antioksidan ve antimikrobiyal özelliklerinin yanı sıra TA98 suşlarında en yüksek dozda antimutajen özelliğe sahip olduğu bulunmuştur. Bu nedenle gilaburu meyvesi tıbbi bir ilaç olarak kullanılabilme potansiyeline sahiptir ancak bunun için daha ileri araştırmalarla desteklenmesi gerekmektedir.

\section{Kaynaklar}

Ahmad, N. and Mukhtar, H., 1999. Green tea polyphenols and cancer: Biologic mechanisms and practical implications, Nutrition Reviews, 57, 3, 78-83.

Altun, M.L., Çıtoğlu, G.S., Yılmaz, B.S. and Çoban, T., 2008. Antioxidant properties of Viburnum opulus and Viburnum lantanagrowing in Turkey, International Journal of Food Sciences and Nutrition, 59, $3,175-180$.

Azirak, S., and Rencuzogullari, E., 2008. The in vivo genotoxic effects of carvacrol and thymol in rat bone marrow cells, Environmental Toxicology, 23, 6, 728-735.

Bakhshi, D. and Arakawa, O., 2006. Effects of UV-b irradiation on phenolic compound accumulation and antioxidant activity in 'Jonathan' apple influenced by bagging, temperature and maturation, Journal of 
Food, Agriculture \& Environment, 4, 1, 7579.

Benzie, I.F.F. and Strain, J.J., 1996. The ferric reducing ability of plasma (FRAP) as a measure of "Antioxidant power; The FRAP assay, Analytical Biochemistry, 239, 70-76.

Bolat, S.ve Özcan, M.,1995. Gilaburu (Viburnum opulus L.) Meyvesinin Morfolojik, Fenolojik ve Pomolojik Özellikleri ile Kimyasal Bileşimi. Türkiye II. Ulusal Bahçe Bitkileri Kongresi, Ç.Ü. Ziraat Fak. Yay, Cilt I., Adana. 72s.

Bubulica, M.V., Anghel, I., Grumezescu, A.M., Saviuc, C., Anghel, G.A., Chifiriuc, M.C., Gheorghe, I., Lazar, V., and Popescu, A., 2012. In vitro evaluation of bactericidal and antibio film activity of Loniceratatarica and Viburnum opulus plant extractson Staphylococcus Strains, Farmacia, 60, 1, 80-91.

Burnaz, N., 2007. Viburnum opulus ve $V$. orientalebitki ekstraktlarının kimyasal bileșimi ve biyolojik aktiviteleri, Yüksek Lisans Tezi, Karadeniz Teknik Üniversitesi Fen Bilimleri Enstitüsü, Trabzon. 66s.

Buyukleyla, M, and Rencuzogullari, E., 2008. The effects of thymol on sister chromatid Exchange, chromosome aberration and micronucleus in human lymphocytes, Ecotoxicology Environmental Safety, Doi:10.1016/j.ecoenv.2008.10.005.

Cemeroğlu, B., 1992. Meyve ve sebze işleme endüstrisinde temel analiz metotları. Ankara: Biltav Yayınları.

Česonienė, L., Daubaras, R., Venclovienè, J. and Viškelis, P., 2010. Biochemical and agrobiological diversity of Viburnum opulus genotypes, Central European Journal of Biology, 5, 6, 864-871.

Česoniene, L., Daubaras, R., Viškelis, P. and Šarkinas, A., 2012. Determination of the total phenolic and anthocyanin contents and antimicrobial activity of Viburnum Opulus fruit juice, Plant Foods for Human Nutrition, 67, 3, 256-261.

Česoniene, L., Daubaras, R., Kraujalyte, V., Venskutonis, P.R. and Šarkinas, A., 2014. Antimicrobial activity of Viburnum opulus fruit juices and extracts, Journal fur
Verbraucherschutz und Lebensmittelsicherheit, 9, 2, 129-132.

Eryilmaz, M., Ozbilgin, S., Ergene, B., Sever Yilmaz, B., Altun, M.L. and Saltan, G., 2013. Antimicrobial activity of Turkish Viburnum species, Bangladesh Journal of Botany, 42, 2, 355-360

Franzios, G., Mirotsou, M., Hatziapostolou, E., Kral, J., Scouras, Z.G., and Mavragani, P.T., 1997. Insecticidal and genotoxic activities of mint essential oils, Journal of Agricultural and Food Chemistry, 45, 26902694.

Giusti, M.M. and Wrolstad, R.E., 2001. Anthocyanins characterization and measurement with UV visible spectroscopy, Current protocols in food analytical chemistry. Editor: Wrolstad, R. E. New York: Willey.

Hızlısoy, H., 2009. Çeşitli mikroorganizmalar üzerine gilaburunun antimikrobiyal etkisinin incelenmesi. Erciyes Üniversitesi, Sağlık Bilimleri Enstitüsü, Yüksek Lisans Tezi.

Ipek, E., Tuylu, B.A., and Zeytinoğlu, H., 2003. Effects of carvacrol on sister chromatid exchances in human lymphocyte cultures, Cytotechnology, 43, 145-148.

İskender, N.Y., 2007. Türkiye Doğal Viburnum L. (Caprıfoliaceae) türlerinin uçucu yağ bileşimleri ve antimikrobiyal aktiviteleri, Yüksek Lisans Tezi, Karadeniz Teknik Üniversitesi Fen Bilimleri Enstitüsü.

Koliopoulos, G., Pitarokili, D., Kioulos, E., Michaelakis, A. and Tzakou, O., 2010. Chemical composition and larvicidal evaluation of Mentha, Salvia, and Melissa essential oils against the West Nile virus mosquito Culex pipiens, Parasitol Research, $107,2,327-35$.

Kraujalyte, V., Venskutonis, P.R., Pukalskas, A., Cesonienè, L. and Daubaras, R., 2013. Antioxidant properties and polyphenolic compositions of fruits from different European cranberrybush (Viburnum opulusL.) genotypes, Food Chemistry, 141, 3695-3702.

Maron, D.M. and Ames, B.N., 1983. Revised methods fort he Salmonella mutagenicity test, Mutation Research, 113, 173-215. 
Mennen, L.I., Walker, R., Bennetau-Pelissero, C. and Scalbert, A., 2005. Risks and safety of polyphenol consumption, The American Journal of Clinical Nutrition, 81, 326-329.

Orakçı, E.E., 2010. Gilaburunun antioksidan aktivitesi. Erciyes Üniversitesi Eczacilik Fakültesi, Bitirme tezi.

Özbek, S., 1977. Genel Meyvecilik. Çukurova Üniv. Ziraat Fak. Yayınları 111, Ders Kitab1 6.

Özcan, H.M., 2010. Fenolik bileşiklerin tayinine yönelik amperometrik esaslı biyosensör hazırlanmasi. Trakya Üniversitesi FenEdebiyat Fakültesi Kimya bölümü. Doktora tezi.

Özçelik, S., 1992. Gida Mikrobiyolojisi Laboratuar Kılavuzu. F.Ü. Fen-Edebiyat Fakültesi Yayınları, Yayın No: 1, Elazı ğ, 135.

Papageorgiou, V., Gardeli, C., Mallouchos, A., Papaioannou, M. and Komaitis, M., 2008. Variation of the chemical profile and antioxidant behavior of Rosmarinus officinalis L. and Salvia fruticosa Miller grown in Greece, Journal of Agricultural and Food Chemistry, 56, 7254-7264.

Paulauskas, A., Žukauskienè, J., Žiaukienė, D. Česonienè, L., Daubaras, R., Kupčinskienè, E.,Lazutka, J.R., Slapšytė, G., Dedonytè, V., Mierauskienè, J., Stapulionytè, A., Paškevičius, A., Levinskaite, L., Švedienè J. and Viškelis, P., 2015. Differentiation of Viburnum accessions according to their molecular, biochemical, genotoxic and microbiological features of importance to selection, Academia Journal of Agricultural Research, 3, 6, 081-093.

Re, R., Pellegrini, N., Proteggente, A., Pannala, A., Yang, M., and Rice-Evans, C., 1999. Antioxidant activity applying an improved ABTS radical cation decolorization assay, Free Radical Biology and Medicine, 26, 1231-1237.
Rezaeirad, D., Bakhshi, D., Ghasemnezhad, M. and Lahiji, H.S., 2013. Evaluation of some quantitative and qualitative characteristics of local pears (Pyrus sp.) in the North of Iran, International Journal of Agriculture and Crop Sciences, 5, 8, 882-887.

Sagdic, O., Aksoy, A. and Ozkan, G., 2006. Evaluation of the antibacterial and antioxidant potentials of cranberry (gilaburu, Viburnum opulus L.) fruit extract, Acta Alimentaria, 35, 4, 487-492.

Sağıroğlu, A., 2003. Bitkisel doğal bileşikler kimyas1, Trakya Üniversitesi FenEdebiyat Fakültesi Kimya bölümü biyokimya anabilim dalı, 12-13.

Stammati, A., Bonsi, P., Zucco, F., Moezelaar, R., Alakomi, H.L., and Von Wright, A., 1999. Toxicity of selected plant volatiles in microbial and mammalian short-term assays, Food Chemistry Toxicology, 37, 813-823.

Şeker, I.T. Ertop, M.H. and Hayta, M., 2016. Physicochemical and bioactive properties of cakes incorporated with gilaburu fruit (Viburnum opulus) pomace, Quality Assurance and Safety of Crops and Foods, 8, 2, 261-266.

Yilmaz, N., Yali, N., Misir, G., Coskuncelebi, K., Karaoglu, S. and Yayli, N., 2008. Chemical composition and antimicrobial activities of the essential oils of Viburnum opulus, Viburnum lantana and Viburnum orientala, Asian Journal of Chemistry, 20, 33243330.

Yürüker, A., 1993. Viburnum orientale Pallas üzerinde fitokimyasal çalışmalar, Doktora Tezi, Hacettepe Üniversitesi Sağlık Bilimleri Enstitüsü, Ankara, 5-15.

Wan-Ibrahim, W.I., Sidik, K. and Kuppusamy, U.R., 2010. A high antioxidant level in edible plants is associated with genotoxic properties, Food Chemistry, 122, 4, 11391144. 